
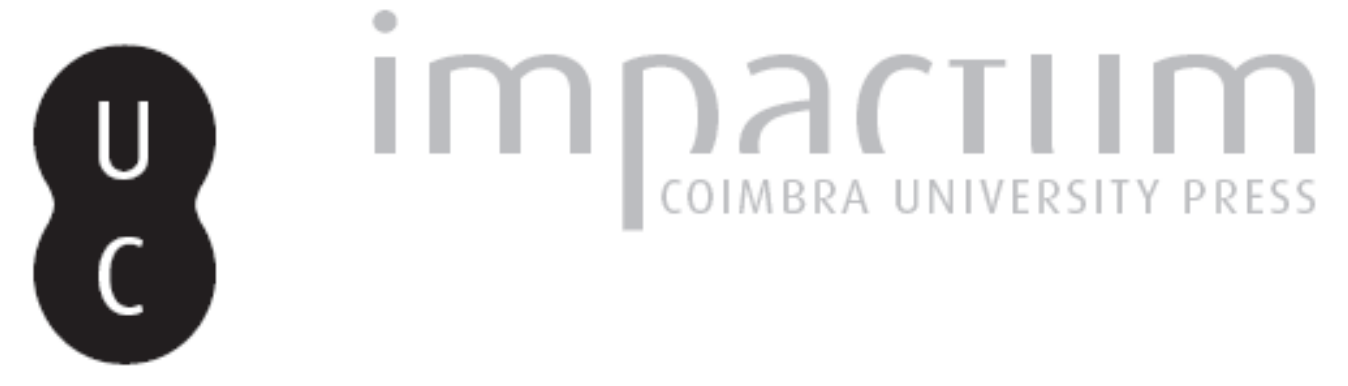

\title{
As Fenícias, de Eurípides (vv. 445-587)
}

Autor(es): $\quad$ Salvador, Evandro Luis

Publicado por: Annablume Clássica; Imprensa da Universidade de Coimbra

URL persistente:

URI:http://hdl.handle.net/10316.2/27885

DOI:

DOI:http://dx.doi.org/10.14195/1984-249X_12_18

Accessed : $\quad$ 26-Apr-2023 14:29:21

A navegação consulta e descarregamento dos títulos inseridos nas Bibliotecas Digitais UC Digitalis, UC Pombalina e UC Impactum, pressupõem a aceitação plena e sem reservas dos Termos e Condições de Uso destas Bibliotecas Digitais, disponíveis em https://digitalis.uc.pt/pt-pt/termos.

Conforme exposto nos referidos Termos e Condições de Uso, o descarregamento de títulos de acesso restrito requer uma licença válida de autorização devendo o utilizador aceder ao(s) documento(s) a partir de um endereço de IP da instituição detentora da supramencionada licença.

Ao utilizador é apenas permitido o descarregamento para uso pessoal, pelo que o emprego do(s) título(s) descarregado(s) para outro fim, designadamente comercial, carece de autorização do respetivo autor ou editor da obra.

Na medida em que todas as obras da UC Digitalis se encontram protegidas pelo Código do Direito de Autor e Direitos Conexos e demais legislação aplicável, toda a cópia, parcial ou total, deste documento, nos casos em que é legalmente admitida, deverá conter ou fazer-se acompanhar por este aviso.

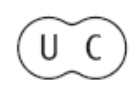


jan/jun

\begin{tabular}{c}
2014 \\
\hline issn 2179-4960 \\
e-issn 1984-249-X
\end{tabular}
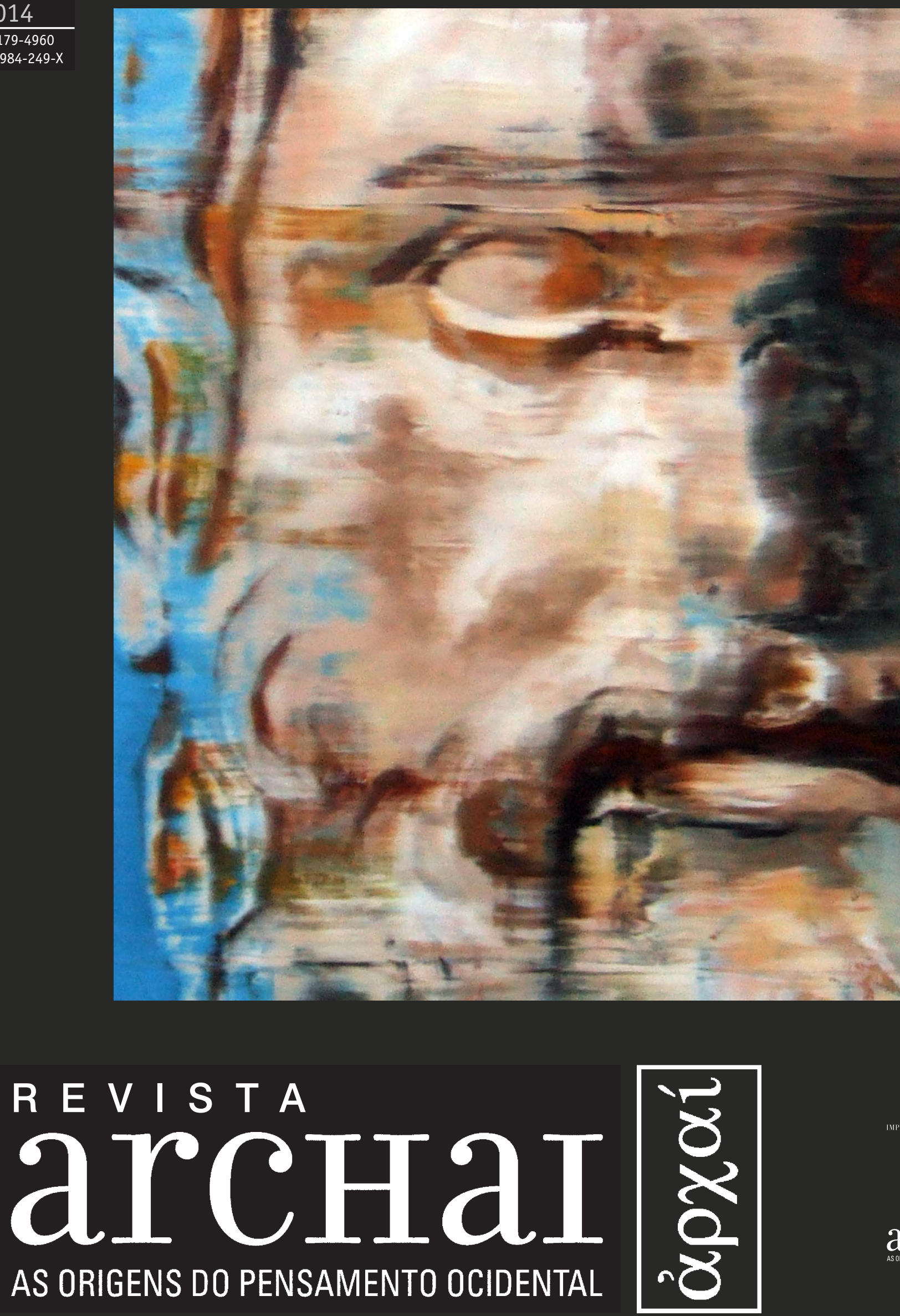
ARCHAI JOURNAL: ON THE ORIGINS OF WESTERN THOUGHT

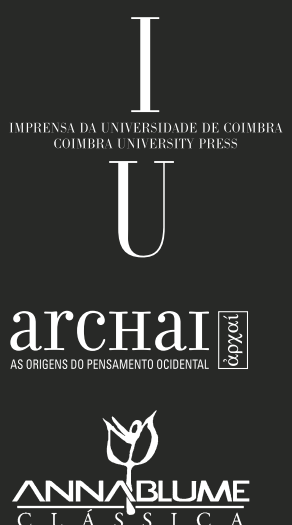




\section{AS FENÍCIAS, DE EURÍPIDES (VV. 445-587)}

SALVADOR E. L. (2014) As Fenícias, de Eurípides(vv. 445587). Archai, n. 12, jan - jun, p. 183-189 DOI: http://dx.doi. org/10.14195/1984-249X_12_18
* Bacharel em Letras pela Universidade Estadual de Campinas (2003), mestre em Lingüística/Letras Clássicas pela Universidade Estadual de Campinas (2006), com bolsa da Capes, e doutor em Linguística/ Letras Clássicas (2010) pela

Universidade Estadual de Campinas, também com bolsa da Capes. Atualmente desenvolve pesquisa de pós-doutorado no Departamento de Linguística da Universidade Estadual Paulista (UNESP).

\section{Evandro Luis Salvador*}

\section{Introdução}

Apresentamos a tradução dos versos 445-587 da tragédia As Fenícias, de Eurípides, localizados na segunda parte do segundo episódio no qual vemos Jocasta, Polinices e Etéocles debaterem acerca das consequências geradas a partir da ruptura do pacto firmado entre seus dois filhos por ocasião da maldição que Édipo lançara contra ambos. Portanto, trata-se de um agôn e, mais do que uma simples seção da tragédia, comum nas obras de Eurípides, a passagem em questão representa o clímax porque, em primeiro lugar, Jocasta o anunciara no prólogo/monólogo, nos versos 80 a 83, e, em segundo lugar, o debate será uma acareação entre os dois desafetos, Etéocles e Polinices, o que provoca uma imensa expectativa em torno desse momento, digamos, "histórico", pois em nenhuma outra tragédia que chegou até nós os dois filhos de Édipo têm uma oportunidade de encontro. Sabemos que eles se encontram $n^{\prime}$ Os Sete contra Tebas de Ésquilo, mas isso ocorre no final da tragédia, quando o confronto entre eles produz um efeito fatal para ambos. Então, é um momento de grande expectativa dramática, sobretudo para Jocasta, que terá a difícil tarefa de evitar um desfecho trágico para sua família, pois os filhos se encontrarão após longo período de animosidade. 
Difícil precisar a geometria espacial da posição dos três personagens no palco. Eles estão em contato visual mínimo, tendo Jocasta no entremeio para separá-los fisicamente. Etéocles tem o ânimo exaltado, com respiração raivosa, e os seus olhos miram o irmão terrivelmente. Não se sabe se Polinices olha para os lados ou para o chão; certo é que ele não olha para o irmão. Jocasta, então, exorta os dois a se entreolharem (verso 458) como o gesto fundamental para o sucesso da mediação, o que, em tese, desarmaria os ânimos ferrenhos dos dois filhos e possibilitaria a execução de dois verbos importantes para o debate: o falar e o ouvir.

0 discurso de Jocasta que antecede 0 debate entre os filhos, ao mesmo tempo em que faz algumas recomendações gerais a eles em termos comportamentais e psicológicos, sinaliza aspectos cênicos interessantes e prepara a audiência para uma experiência tendendo mais fortemente para 0 aspecto intelectivo do que para o emotivo.

Uma questão que emerge em relação à forma dos debates é: teria havido uma audiência sofisticada e preparada para qualquer tipo de debate expresso formalmente nas tragédias de Eurípides? Colocada sobre outro ângulo: a audiência teria a compreensão do debate, em sua forma e conteúdo, expresso de maneira dramática, dado que a formalização discursiva recupera uma dinâmica de debate jurídico? Sobre esse aspecto, para Lloyd (1992, p. 2), os debates nas tragédias de Eurípides absorvem e refletem várias situações da vida contemporânea ateniense, não só situações que envolvem contenda jurídica, mas também os debates políticos e diplomáticos. Bers (1994, pp. 178-9), contrariamente, argumenta que a conexão entre os discursos políticos no Conselho ou na Assembleia, os discursos forenses nas cortes e os demais discursos relativos a outras esferas da vida do cidadão ateniense e o uso de todas essas formas de discurso nas tragédias é incerto. Para ele, identificar uma estratégia retórica num drama como imitador da oratória da vida real é frequentemente vã porque as evidências são esparsas. Da minha parte e considerando que o debate é uma presença marcante nas tragédias euripidianas, seria difícil sustentar que a audiência teatral do final do século $V$ a. C., com a sofística em voga nas últimas décadas do século de Péricles, estivesse completamente alheia a esse fenômeno. 0 discurso de Polinices, por exemplo, conforme Mastronarde (1994, pp. 280-81), é um evidente ataque às concepções sofísticas de verdade/falsidade e justiça/ injustiça. Quando, no verso 472, Polinices associa o adjetivo "injusto" ao substantivo "discurso", ao mesmo tempo em que associa o irmão ao ideário sofístico, alude ao "programa" intelectual dos sofistas, que se baseava no reexame dos valores mais antigos. A insistência de Polinices na acessibilidade e clareza do verdadeiro e do justo em contraposição ao "floreamento" e encantamento dos discursos, doentes em por si mesmos, é uma ataque aberto à retórica pragmática dos sofistas.

Do ponto de vista do conteúdo, temos um conceito delicado: o termo túgavvos, segundo Parker (1998, pp. 145-172), tem etimologia incerta, não é um termo cunhado pelos gregos, mas sabe-se que ele foi introduzido no vocabulário político daquele povo em meados do século VIII a. C., através de Arquíloco, e, originalmente, significava rei, compondo o mesmo campo semântico de $\beta \alpha \sigma i \lambda \varepsilon u ́ s$ e $\alpha$ $v \alpha \xi$, ou seja, os três termos se referiam a um governo monárquico. 0 uso se aplicava a qualquer rei que alcançasse tal condição política por meios legítimos.

No entanto, a partir da primeira metade do século VI a. C., com Sólon, o termo passou a ter uma acepção secundária, pois se referia ao monarca que chegou a tal condição por meios ilegítimos (fraude ou força), usurpando o poder para governar a cidade. Assim, de uma concepção neutra ou positiva, por assim dizer, tirano passou a ter um sentido negativo, para caracterizar aquele que está investido de um cargo real, mas que usurpou um poder que não the pertence legitimamente. A digressão é válida, pois

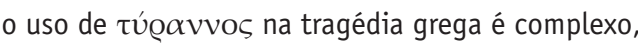
pois flutua entre os significados primário/positivo e secundário/negativo. Especificamente nesta tragédia, o termo e seus correlatos ocorrem nos versos $40,483,506,523-24,549$ e 560-61 e eles variam conforme o contexto em que aparecem. No verso 40, por exemplo, o termo tem um sentido primário porque está sendo aplicado ao exercício do poder por Laio, que herdou o trono legitimamente. Na questão 
Eurípides constrói os personagens trágicos diferentemente da maneira como a tradição heróica os apresenta nas suas linhas gerais. Despojando as figuras lendárias de sua aura heróica e aristocrática, o poeta as aproxima da realidade do cidadão comum. Jocasta é um claro exemplo dessa mudança, pois, segundo Gentili (1995, p.143), ela está vinculada à ética do real, da vida cotidiana, uma ética que é pessimista no pensamento, mas otimista na vontade, que tendia a desmistificar os mais elevados valores ético-religiosos das aristocracias arcaicas, já em declínio, substituindo-os por um ideal menos elevado, mas consoante à nova realidade histórica; um ideal de cidadão democrático que se move dentro do respeito à justiça e aos interesses da cidade.

\section{Etéocles}

Eis-me, mãe: concedendo-lhe um favor vim aqui.

0 que me é necessário fazer? Alguém deve falar primeiro.

Pois em torno das muralhas <

$$
\text { > e dos pares de batalhões }
$$

interrompi a disposição para que ouvisse teu

arbítrio imparcial, com o qual, sob uma trégua, me convenceste a deixar

este aí a adentrar os muros.

\section{Jocasta}

Espera: a pressa, certamente, não ajuda a justiça.

Mas discursos calmos produzem uma sabedoria muito maior.

Cessa esse olhar sinistro e a respiração raivosa:

Pois não estás olhando para a cabeça decepada da Górgona,

estás vendo o teu irmão em regresso.

E tu, por tua vez, volta a face na direção de teu irmão,

Polinices! Pois mirando para o mesmo ponto falarás

e ouvirás os discursos dele da melhor maneira.

Contudo, ofereço para os dois um sábio conselho:

Quando um amigo foi exasperado por outro,

ao encontrar-se com ele, olhos nos olhos,

deve ter em conta somente duas coisas:

o motivo pelo qual está presente e esquecer as hostilidades de outrora.

Tuas palavras primeiramente, meu filho Polinices,

pois vieste liderando um exército de argivos,

como dizes, por causa de injustiças cometidas contra ti.

Que haja, dentre os deuses, um juiz mediador de males! 


\section{Polinices}

0 discurso da verdade é, por natureza, simples,

e uma causa justa não precisa de grandes floreados:

tem em si mesma a medida exata: o discurso injusto,

pelo contrário, requer remédios perspicazes, pois em si é doente.

Da minha parte, considerando a herança paterna no que

diz respeito a mim e a este, necessitei fugir por causa

das maldições imprecadas contra nós, naquele tempo, por Édipo:

1. Leia-se: o poder autocrático conquistado mediante fraude. Etéocles eleva o substantivo ao nível de divindade. Jocasta apontará a insanidade do filho mais adiante.

por iniciativa própria, decidi partir desta terra

cedendo para que este governasse a pátria durante o ciclo de um ano,

ao término do qual retomaria e governaria a minha parte,

sem hostilidade contra ele, nem inveja, muito menos sofrer

ou cometer qualquer mal, como os que estão acontecendo.

Contudo, após aprovar o acordo e jurar pelos deuses,

nada fez para cumprir o nosso pacto. Pelo contrário,

ainda reina tiranicamente e detém a minha parte da herança.

Então, se retomar o que me é devido, farei o seguinte:

direi ao exército para deixar esta terra e

habitarei a minha casa após retomar minha parte;

e, para ele, cederei novamente por igual período de tempo.

Não destruirei a pátria, nem conduzirei

contra as torres escadas para galgá-las,

coisas que farei se não encontrar justiça.

Invoco as divindades como testemunhas do que disse,

pois estou agindo com justiça, mas sou privado,

injustamente, da minha pátria da maneira mais ímpia possível.

As coisas que acabei de dizer, mãe, o fiz sem muita elaboração

nos argumentos, pois me parece, tanto aos sábios

quanto aos mais simples, que elas estão amparadas na justiça.

\section{Coro}

Para mim, mesmo não tendo tido educação helênica, ainda assim considero que falaste inteligentemente.

\section{Etéocles}

Se algo fosse, ao mesmo tempo, belo e sábio para todos,

não haveria contenda entre os homens;

Mas nada é nem semelhante nem igual para os mortais

a não ser o uso das palavras; e este não é o caso em questão.

Da minha parte, mãe, esconderei nada na minha fala:

Eu iria até o éter, onde surgem os astros,

e até às camadas mais profundas da terra - seria capaz disso! -

só para possuir a maior das divindades: a Tirania ${ }^{1}$.

Portanto, mãe, não desejo ceder esse bem

para ele mais do que retê-lo para mim:

seria covardia ceder o maior bem 
para ficar com o menor. Além do mais, uma coisa me envergonha:

este aí vem com um exército para devastar a terra

e conseguir aquilo que deseja;

seria ignominioso para Tebas se, por medo da lança dos micênicos, eu retrocedesse e repassasse para ele o meu cetro.

É necessário a ele, mãe, buscar a reconciliação

não com armas: as palavras são capazes de alcançar, também,

o mesmo alvo que a espada dos inimigos.

Contudo, se ele quer habitar esta terra de outro modo, seja!

Não deixarei voluntariamente de governar

se a mim isso é possível; devo ser escravo dele em algum momento?

Então, que venham o fogo e as espadas;

Preparai os corcéis e ocupai a planície com as carruagens, pois não cederei minha condição de tirano para este aí.

Se é necessário ser injusto por causa do poder tirânico,

ser injusto é a coisa mais bela; para o restante, é preciso ser pio.

\section{Coro}

Não se deve ter eloqüência a não ser para boas ações:

isso não é bom, mas horrível para a justiça.

\section{Jocasta}

ó filho, nem tudo é ruim na velhice,

Etéocles: a experiência, contudo,

tem algo mais sábio para dizer em relação aos jovens.

Por que persegues a mais funesta das deidades,

a Ambição, filho? Não faças isso: é uma deusa injusta.

Pois em muitas casas e cidades prósperas

ela entrou e saiu após arruinar aqueles que a serviram.

Por causa dela estás louco. A coisa mais bela, filho, é isto:

honrar a Igualdade, a qual sempre reúne amigos com amigos,

cidades com cidades e aliados com aliados.

A igualdade é, por natureza, lei para os homens;

Contudo, o menor sempre se coloca como inimigo para o maior

e disso resulta o começo das hostilidades.

Com efeito, a medida e a unidade dos pesos a Igualdade

estabeleceu para os homens, assim como os números,

e o olho obscuro da noite e a luz do sol

caminham em igualdade durante o ciclo de um ano:

e nenhum deles, quando prevalece, suscita o ódio.

Se o sol e a noite servem aos mortais,

por que tu não suportas ter igual parte na herança

e $†$ ceder o que é devido a ele $†$ ? Onde está a justiça nisso?

Por que a tirania, injusta afortunada,

veneras em excesso e a tens como superiora?

Para ser olhado com respeito? Então é em vão! 
Ou desejas te aborrecer possuindo muitos bens no palácio?

0 que é a abundância? Apenas um nome;

pois, para os sábios, basta o suficiente;

Os mortais não são proprietários de suas riquezas;

custodiamos as coisas enviadas pelos deuses,

e eles, quando assim desejam, as tomam de volta.

\{a prosperidade não é durável, mas efêmera.\}

Vamos! Se ao colocar duas perguntas te questionasse

qual das duas desejas: continuar a ser um tirano ${ }^{2}$ ou salvar a cidade,

escolherias a primeira? Pois se esse aqui te vencer

e as lanças argivas prevalecerem sobre as dos Cadmeus,

verás esta cidade tebana dominada,

assim como muitas donzelas cativas

sendo violentadas pelos homens inimigos.

Então, a riqueza que buscas possuir

será destrutiva para Tebas, pois és ambicioso.

Isso é o que tinha para te dizer; a ti então, Polinices, direi:

Adrasto te prestou favores estultos,

e vieste tu, também irrefletidamente, para destruir a cidade.

Bem, se conquistares esta terra - e que isso jamais aconteça -, pelos deuses, como erigirás troféus a Zeus?

E como realizarás sacrifícios, se conquistares tua própria pátria?

Como escreverás nas armas dos vencidos junto ao Ínaco:

“Polinices, após incendiar Tebas, oferta

estes escudos aos deuses?"Jamais, filho, tal fama

advenha para ti dentre os Helenos.

Se, pelo contrário, sofreres uma derrota para teu irmão,

como voltarias a Argos deixando inúmeros cadáveres?

Por certo alguém dirá: “0́ Adrasto, porque impuseste funestas

alianças matrimoniais - através do casamento de uma filha -

fomos destruídos". Persegues dois males, filho:

ser privado daqueles e de cair no meio desta guerra.

Renunciem ao excesso, renunciem: a irreflexão dos dois, quando coincidem, é o mal mais odioso.

2. Marcamos a distinção aspectual entre os infinitivos: o presente

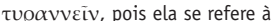
continuidade do exercício tirânico do filho, e o aoristo $\sigma \tilde{\omega} \iota \sigma \alpha \mathrm{L}$, que pressupõe a negação da tirania como ação pontual para salvar a cidade.

\section{Coro}

ó deuses, afastai esses infortúnios para longe e concedei o entendimento para os filhos de Édipo!

\section{Referências bibliográficas}

AMIECH, C. (2004) Les Phéniciennes d'Euripide. Paris, L’Harmattan.

BERS, V. (1994) "Tragedy and Rhetoric". In: Persuasion: Greek rhetoric in action. Ian Worthington (ed.). Londres, Routledge, p. 176- 195.
CRAIK, E. (1988) Euripides: Phoenician Women. Aris \& Phillips.

GENTILI, B. (1995) Poesia e pubblico nella Grecia antica. Roma-Bari, Editori Laterza.

LLOYD, M. (1992) The Agon in Euripides. Oxford, Clarendon Press. 
MASTRONARDE, D. (1994) Phoenissae. Cambridge, University Press.

MEDDA, E. (2006) Euripide: Le Fenice. Milano, RCS Libri S.p.A.

PARKER, V. (1998) "Túrannos: the semantics of a political concept from Archilochus to Aristote". In: Hermes, vol. 126 , no. 2, p. 145- 172

Artigo recebido em setembro de 2013, aprovado em novembro de 2013. 